\title{
Study on the projectized-teaching of fine chemical industry
}

\author{
Wangxi Fan ${ }^{1, a}$, Zefang $\mathrm{Li}^{2, \mathrm{~b}^{*}}$, Qiaoling Wang ${ }^{1, \mathrm{c}}$ \\ ${ }^{1}$ Department of Chemical and Environmental Engineering, Wuhan Bioengineering Institute, Wuhan \\ 430415, China \\ ${ }^{2}$ Institute of Computer Technology and Software Engineering, Wuhan Polytechnic, Wuhan 430074, \\ China \\ a12320575@qq.com, ${ }^{\mathrm{b}}$ 408729494@qq.com, ${ }^{\mathrm{c}}$ 517298284@qq.com \\ ${ }^{*}$ corresponding author
}

Keywords: project teaching method; practice; chemical engineering specialty; transformation and development.

\begin{abstract}
This study aims to further investigate the application and implementation of project teaching method in the teaching of chemical engineering specialty course (i.e. fine chemicals industry). A complete project system for fine chemicals industry course and the four-dimensional evaluation system for students were established. Based on the comprehensive discussion of 4 steps of the implementation of project, it is reasonable to infer that the vigorously promotion and widely application of project teaching method will be one of the most efficient methods in the development of applied talents training mode.
\end{abstract}

\section{Introduction}

Project Teaching Method (PTM) originated in the United States. It was popular in colleges and enterprises of Germany in the 1980s due to its efficient of training of the comprehensive ability of occupation, including key ability. Moreover, it has been widely promoted and developed as a typical action oriented teaching methods in some developed countries, such as America, France, United Kingdom and others ${ }^{[1-3]}$.

The course teaching content and the actual project management in the factory can be combined by PTM, which can bring learning and training together perfectly. The successful implementation of the project will not only give the students a sense of achievement and success of the application but also avoid the phenomenon of dull as ditch water and theory divorced from practice led by the traditional teaching mode ${ }^{[4,5]}$. Furthermore, PTM is conducive to mobilize the enthusiasm of students fully and stimulate the students' desire to learn. At the same time, the students' autonomous learning and team spirit, ability in analytical skill and solving problems independently can be cultivated perfectly. Finally but not the last, students can understand and touch the real society, the distance between the real factory and the classroom will be reduced significantly in PTM. PTM has been widely researched and practiced in many universities and training institutions domestic and foreign, such as Henan Institute of Engineering, Hebei Institute of science and technology, Shandong Provincial cadre management college, Wuxi Institute of Technology and other institutions till now. PTM was mainly applied in the courses teaching of animation, machinery, foreign language, marketing, management and other professional theory and practical training. However, the application of PTM in chemistry and chemical engineering courses has never been reported in the literature ${ }^{[6-12]}$.

In this study, the application and practice of PTM in the course of engineering chemistry is discussed with the example of "Fine Chemicals Industry (FCI)". 


\section{The practice of project teaching in FCI}

\section{Introduction to FCI}

FCI is one of the core courses of chemical engineering specialty (specialized direction: fine chemical engineering). The research objects of FCI mainly included the physical and chemical properties, manufacturing technology, practical applications of fine chemicals and the research and development of new products. Pesticide, dye, paint (including paint and ink), reagents and high purity chemicals, food and feed additives, adhesives, catalysts and additives, chemical raw materials and chemicals, functional polymer materials and other fine chemicals productions were studied in FCI. Every one of the mentioned above has formed a relatively complete and independent knowledge system due to the rapid development of chemical technology. Based on these premises, it is reasonable to infer that the FCI course has the potential advantages of implementing of PTM.

\section{Preparation and design of Project}

Decomposed the teaching task with the real demand of factories and enterprises, and integrated the knowledge to be taught into the project perfectly after the gap between teaching content and factories were analyzed systematic by teachers and engineering and technical personnel. These are the core requirements of PTM. The demand analysis and decomposition of knowledge and the establishment of the project are the core steps of PTM ${ }^{[13-14]}$.

Seven feasible projects were integrated and designed for the FCI course after a comprehensive analysis of the common organic chemical products in the market and FCI textbook. These projects take into account not only the inheritance of FCI knowledge but also the actual market applications of fine chemical products. The projects with practiced and optimized are summarized in Table 1.

Table 1 Seven projects of FCI course

\begin{tabular}{|c|c|c|c|}
\hline No. & Project name & Coverage of knowledge & Class hours \\
\hline 1 & $\begin{array}{l}\text { Production technology of Linear } \\
\text { Alkylbenzene Sulfonate (LAS) }\end{array}$ & Anionic surface-active agent & $6-8$ \\
\hline 2 & $\begin{array}{l}\text { Production technology of } \\
\text { 2,6-Di-tert-butyl-4-methylphenol } \\
\text { (BHT) }\end{array}$ & $\begin{array}{l}\text { Antioxidant for processing } \\
\text { of synthetic material }\end{array}$ & 6 \\
\hline 3 & $\begin{array}{l}\text { Production technology of } \\
\text { Simazine }\end{array}$ & Herbicide (pesticide) & $6-8$ \\
\hline 4 & $\begin{array}{l}\text { Production technology of } 1227 \\
\text { (Dodecyl Dimethyl Benzyl } \\
\text { Ammonium Chloride) }\end{array}$ & $\begin{array}{l}\text { Fine chemical products for } \\
\text { processing of water }\end{array}$ & $6-8$ \\
\hline 5 & $\begin{array}{l}\text { Production technology of Sorbic } \\
\text { Acid }\end{array}$ & Food additives & $6-8$ \\
\hline 6 & $\begin{array}{l}\text { Production technology of laundry } \\
\text { powder }\end{array}$ & $\begin{array}{l}\text { Domestic and industrial } \\
\text { detergents }\end{array}$ & $6-8$ \\
\hline 7 & $\begin{array}{l}\text { self-selected project: the research } \\
\text { and development of a new } \\
\text { product }\end{array}$ & $\begin{array}{l}\text { If necessary, temporary } \\
\text { design. }\end{array}$ & $6-8$ \\
\hline
\end{tabular}

The coverage of knowledge and the principles of easy to difficult and gradual should be fully reflected in the proceeding of project design. At the same time, the implementation steps and levels of the project should be fully considered.

\section{Implementation of project}

All the students should complete the specified or optional items by integration and application of existent and new knowledge in order to achieve the purpose of mastering the knowledge and train the practice skill. These are the core requirements for teachers of PTM. Completed the task 
independently or in the form of group collaboration is the core step for students in PTM, which can cultivate students' comprehensive quality efficiently.

56 to 64 class hours are usually set for the FCI course of chemical engineering specialty (specialized direction: fine chemical engineering), which aims to training applied talents of students. Taking into account the operability of all the project of FCI course, the first 8 class hours is arranged to carry out theoretical teaching. In which, the basic knowledge, basic concepts and basic research methods are briefly introduced by the teacher, so that students have a preliminary understanding for those. And then, each project is completed in 6 - 8 class hours (ca. 1 or 2 weeks) starting from the 9th class hours. The all projects shown in table 1 will be completed in a whole semester. The allocation of class hours in detail is summarized in Table 1.

General process of fine chemical industry development are summarized in Fig. 1. Based on project 6 in table 1 (i.e. the production technology of laundry powder), the implementation of PTM was discussed systematically.

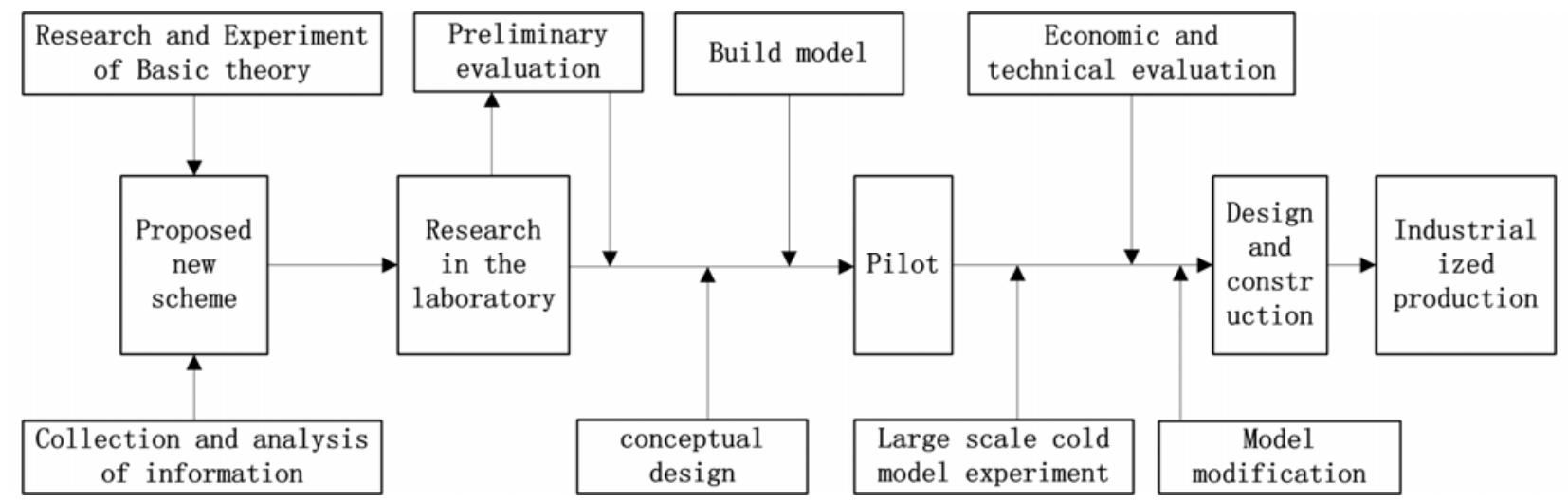

Fig. 1. General process of fine chemical industry development

Step 1: project introduction and task determination.

Before the implementation of PTM in project 6, the objective and significance of the project, the coverage of knowledge points should be explained in detail by a guidance teacher. Moreover, the analysis of knowledge requirement are preached briefly. At the same time, the guidance teacher should not only encourage students to use divergent thinking, give full play to the imagination and innovative learning, but also require students to pay attention to the scientific nature, rigor and integrity of knowledge system. The tasks of this project are decomposed according to the characteristics of the team members by each project team leader. The role of each team member, cooperative mode and every time node of each task are defined.

Step 2: information collection and analysis.

There are a lots of literature and patents of the production technology of laundry powder. The success or failure of the project implementation is determined directly by the quality of information collection and analysis. All team members should be involved in the process of information collection and analysis. In order to improve quality of acquired information as much as possible, the appropriate information according to the main body of the project are selected elaborately and deeply discussed by everyone in the group.

Step 3: establish project.

This step is the core section in the whole project implementation process. In this step, all team members should show their own idea, should participate in the discussion of the design of the companion. They have to collect more appropriate information if necessary. Finally, a summary report or design plan that can be submitted was sorted and optimized. The teachers and enterprise personnels can provide guidance on professional knowledge and product market in this step, respectively.

Step 4: student assessment and project evaluation.

Project evaluation was actualized in the process of group communication. Relevant technicians or business managers were invited to participate in this step. The communication was presided over 
by the teacher. In which, the achievement of student and/or the quality of project were evaluated from the following four aspect: student self-evaluation, classmate evaluation, teacher evaluation, enterprises evaluation. This kind of student evaluation method were defined as four-dimensional evaluation system.

In the proceeding of the four-dimensional evaluation system, representative selected by each group should share or display their own project design and the gains or losses in the implementation process of the project one by one via multimedia equipment. At the same time the student self-evaluation were completed. And then, recommendations or opinions on the work of the project group are made by students from other groups, and provided the evaluation of the classmates. Subsequently, enterprises evaluation is carried out by relevant business management or technical personnel according to the actual application of organic chemical products or the actual operation of the production line. In the end, teacher evaluations are carried out according to the comprehensive utilization of knowledge, the solution of practical problems and innovative. Moreover, the improvement measures of the project should pointed out combined with the evaluation of enterprises by teacher. The scores of individual items in each group are composed of four parts mentioned above. The scores of individual items of each group are composed of four parts mentioned above.

\section{Conclusion}

The gap between the teaching of classroom and the actual production of engineering will decrease rapidly due to the implementation of PTM. It is attributed to the vigorously promotion and widely application of PTM in the teaching of chemical engineering courses. PTM is famous for the comprehensive training of students' team spirit and practical ability. The successful application of PTM is not only beneficial to significantly reduce the distance between the factory and classroom, is advantageous to the realization of combination of teaching process and the production process, is convenient to the realization of combination of professional curriculum content and occupation standard, but also is convenient to advance contact the society for students. All these measures will lead a good base to all students to go to work in the future.

Based on the characteristics of PTM and the market orientation of student employment, it is reasonable to infer that the vigorously promotion and widely application of PTM will be one of the most efficient methods in the development of applied talents training mode under promoting the transformation and development background till now.

\section{Acknowledgments}

The authors would like to thank the referees for their valuable comments and suggestions. This work was supported by the Education Department of Hubei Province (No. 2013395).

\section{References}

[1] Y. H. Luo, L. D. Xing, Q. Wang, E. L. Dong, X. G. Weng, H. C. Liu, The reform of curriculum project based on project teaching method. J. Electr. Electr. Educ. 6 (2009) 10-14.

[2] S. B. Ransom, The science fair as an aid to project teaching. Sci. Educ. 3 (2006) 133-138.

[3] G. M. Montes, M. D. C. R. GáMez, B. M. Escobar, J. O. GarcíA, Final Project Teaching in Higher Education within Civil Engineering: New Perspective. J. Prof. Issu. Eng. Educ. Pract. 2 (2007) 94-98.

[4] K. Kataoka, M. Taguchi, A. Takeshita, The Study and Practice of Project Teaching of Comprehensive Training in Mould Major. Liaon. High. Voca. Tech. Ins. J. 3 (2011) 295-297.

[5] G. H. Traftost, Project Teaching in General Science 1. Sch. Sci. Math. 4 (2010) 315-322.

[6] W. X. Fan, Z. F. Li, Current situation and Countermeasures of teachers' Continuing Education in private colleges in Hubei Province. Conti. Edu. Res. 3 (2012) 97-99. 
[7] A. Sa-Ngiamwibool, Raising learner awareness of local wisdom in tour-related project teaching. Indo. J. Appl. Ling. 2 (2012) 1-16.

[8] A. E. Rivet, J. S. Krajcik, Achieving standards in urban systemic reform: An example of a sixth grade project-based science curriculum. J. Res. Sci. Teach. 41 (2004) 669-692.

[9] L. H. Tong, W. U. Jian, Study and Practice on the Project Teaching Based on the Course of The Chemical Equipment Application and Maintenance. Guan. Chem. Ind. 19 (2015) 31-37.

[10] S. Q. Zhang, Project Setting and Content Design of Project Teaching Method in "Product-oriented, Project Progressive" MCU Course. J. Chan. Vocat. Coll. of Inform. Tech. 4 (2010) 166-169.

[11] M. Wang, M. Zhou, Development of the training program for excellent advanced manufacturing technology engineers by project-teaching method. Chi. Mod. Educ. Equi. 10 (2010) 32-35.

[12] Q. Wan, G. R. Sui, Guiding an Active Role of University New Media Communication-New Media Quality Education. J. HuBei TV Uni. 6 (2013) 27, 51.

[13] C. Johnson, J. Fargo, J. B. Kahle, Cumulative and Residual Impact of a Systemic Reform Program on Teacher Change and Student Learning of Science. Sch. Sci. Math. 3 (2010) 144-159.

[14] K. R. Wang, Application of project teaching method in course of Chinese medical preparation. Chi. Medi. Hera. 33 (2012) 160-161. 